\title{
Removal of Iron and Manganese from Groundwater by Adsorption on Agricultural Residues and Natural Waste Materials
}

\author{
Ahmed M. Abo-Elmagd, Badr El-Din E. Hegazy and Ahmed Y. Bakry \\ Sanitary and Environmental Engineering, Faculty of Engineering at Shoubra, Benha University, Egypt. \\ Correspondence Author: Ahmed M. Abo-Elmagd, Assistant Professor of Sanitary and Environmental Engineering, Faculty of Engineering at Shoubra, Benha \\ University, Egypt \\ E-mail:- ahmedcivil2003@yahoo.com
}

Received date: 15 June 2019, Accepted date: 22 August 2019, Online date: 29 August 2019

Copyright: () Ahmed M. Abo-Elmagd et al., This is an open-access article distributed under the terms of the Creative Commons Attribution License, which permits unrestricted use, distribution, and reproduction in any medium, provided the original author and source are credited.

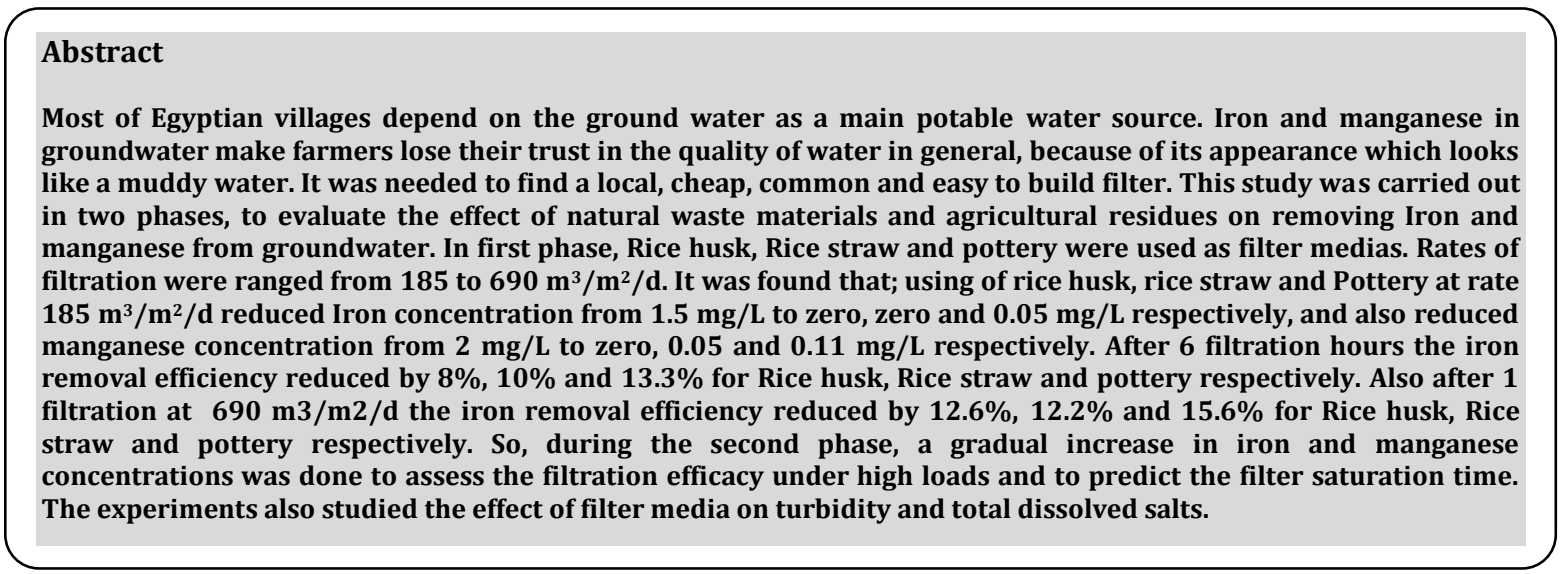

Keywords: Rice husk, Rice straw, pottery, iron, manganese, groundwater, filter

\section{INTRODUCTION}

Nowadays groundwater plays an essential role in the generation of clean drinking water supply. In simple words even countries which has fresh surface water resources, only the neighboring areas can use fresh water, whereas the other regions still have to depend on the groundwater. Groundwater has advantages and drawbacks, soil layers partially filter groundwater, so it is most comfortable in treatment and so little microorganisms can live there, on the other hand, groundwater wash the soil, so it has many dissolved salts (UNESCO, 2004).

Iron and manganese are among the first five elements found abundantly in the earth's crust. Iron is the fourth element and manganese are the second element. (Silver 1993; WHO 1996),

People complain the strange taste and brown color which looks like muddy water, so it is aesthetically unacceptable. The mechanical troubles for softeners, heaters or boilers can occur and softening or heating efficiency will be decreased due to the precipitation of iron and manganese (Takerlekopoulou and Vayenas, 2006). Moreover, iron deposits cause clogging of well screens and pipes. WHO has approved the treatment of water if concentrations of iron and manganese are higher than $0.3 \mathrm{mg} / \mathrm{L}$ and $0.1 \mathrm{mg} / \mathrm{L}$.

Several techniques have been used for removal of Iron \& Manganese from ground and surface water that include Oxidation by aeration or by oxidizing agents, alkalinization, ion exchange, membrane processes, biological filtration or using adsorption method (Barloková D \&Ilavský J, 2010).

The high cost of some material used in the removal of Iron and manganese like activated carbon had led many researchers to look for more economical, efficient and practical adsorbent materials (Sotelo et al., 2002).

The availability of agricultural residues and other natural waste materials, in addition to the desire to dispose of it make them good sources of cheap raw adsorbent materials. Materials containing carbons such as fly ash (BasavaRao and Ram Mohan Rao, 2006), Bituminous coal, straw, coconut shell, wood, tire.etc are some new adsorbents. Rice husk contains about $20 \%$ silica, so it 
has been nominated as a good adsorbent for many metals (Chuah et al., 2005). Also, rice straw is mainly composed of cellulose about (35\%), hemicellulose about (25\%) and lignin about (12\%) (Binod et al., 2010).

Many attempts were done, to convert rice straw and rice husk to animal feed, rice straw seem to add a little bit benefits to animal feed but rice straw not preferred because of its induced irritation for the digestive tract. Most of the rice straw is burned in open fields, which causes severe air pollution.

The annual production of rice husk all over the world is 50 to 100 million ton. So, the amounts of rice husk available are so far in excess of any local uses and have posed disposal problems. Dry rice husk contains about $80 \%$ organic matter and about 15 $\%$ mineral ash. The mineral ash is $94.5-96.34 \%$ SiO2. (Daifullah et al., 2003)

K.K. Wong et al. studied the effect of $\mathrm{pH}$, temperature and other parameters on the removal of heavy metals from wastewater by rice husk. They reported that the treated rice husk with tartaric acid had a high efficacy on removal of lead and copper from wastewater.

The objective of the present investigation is to study the performance of pressure filter which contains rice husk, rice straw or pottery individually to adsorb $(\mathrm{Mn}+2)$ and $(\mathrm{Fe}+3)$ from groundwater and to study the effect of different process conditions on the filtration.

\section{MATERIALS AND METHOD}

This study was carried out in Qaha Water Treatment Plant- Qalubia governorate, Egypt, which uses oxidation method to remove iron and manganese from groundwater. The filter consists of a stainless steel circular cylinder with an inside diameter of $20 \mathrm{~cm}$ and a height of $30 \mathrm{~cm}$. The used media were placed in the filter individually through the top opening. Inlet and outlet valves were provided with very fine screen to prevent media from escaping as shown in Fig. (1) and Fig. (2).



Fig.1: A schematic illustration of the pilot

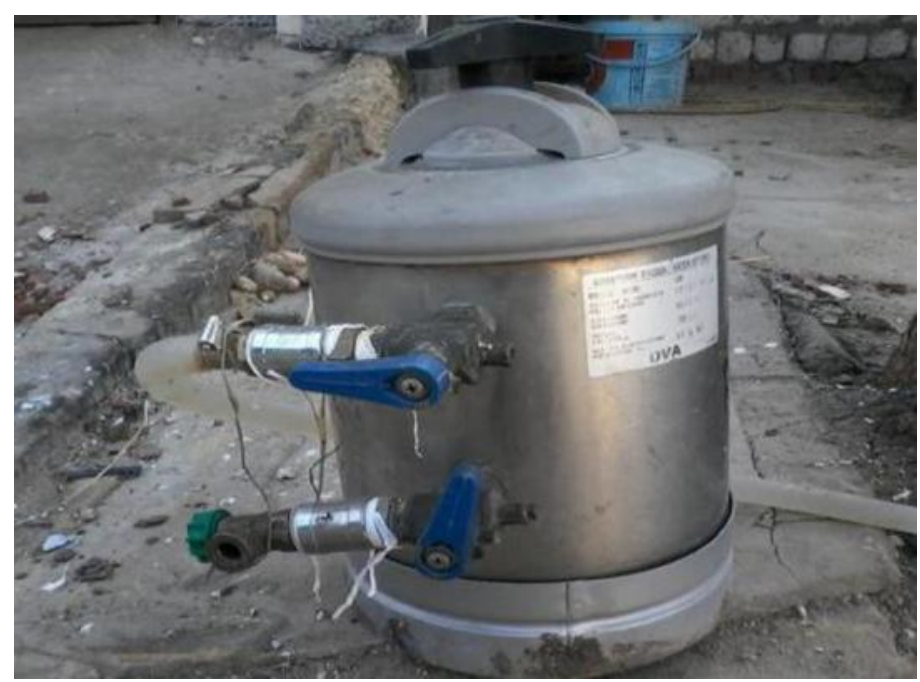

Fig.2: a photographic picture of the pilot

\subsection{Properties of filter media:}

\subsubsection{Rice husk}

Common physiochemical properties of Rice husk are shown in table (1) (BhavnaMistry, 2016). The percentage of the contents depends on rice type, soil and climatic conditions. Rice husk contains a large amount of hydrocarbons as cellulose and lignin. 
Table 1: Typical analysis of rice husk.

\begin{tabular}{|c|c|}
\hline Properties & Rice husk \\
\hline Bulk density (kg/m3) & $60-160$ \\
\hline Hardness (Mohr's scale) & $5-6$ \\
\hline Ash. \% & $22-29$ \\
\hline Carbon. \% & $35-40$ \\
\hline Hydrogen. \% & $4-5$ \\
\hline Oxygen. \% & $30-36$ \\
\hline Nitrogen. \% & $0.23-0.32$ \\
\hline Sulphur. \% & $0.04-0.08$ \\
\hline Moisture. & $8-9$ \\
\hline
\end{tabular}

\subsubsection{Rice straw}

Rice straw was obtained locally from the rice field. The used rice straw was washed several times and allowed to dry, then was shredded into small slides.

\subsubsection{Pottery}

Pottery was screened using two sieves, $30 \times 30 \mathrm{~mm}$ and $40 \times 40 \mathrm{~mm}$. Broken and flatted ceramics were removed, total surface area of one piece was about $38.48 \mathrm{~cm} 2$, the total volume of one piece was approximately $15.45 \mathrm{~cm} 3$.

\subsection{Groundwater}

The pilot received groundwater from Qaha WTP well, located in Egypt, for about ten months from November to August. Several laboratory tests have been performed to characterize the physical properties of the groundwater used in the study. Table (2) shows a summary of the features of groundwater through the study period.

Table 2: Properties of raw groundwater through the study period.

\begin{tabular}{|c|c|}
\hline Properties & Range \\
\hline Iron concentration mg/L & $1.5-2$ \\
\hline Manganese concentration mg/L & $1.5-2$ \\
\hline Total dissolved salts (TDS) $\mathrm{mg} / \mathrm{L}$ & $550-600$ \\
\hline Turbidity NTU & $3-5$ \\
\hline Conductivity $\mathrm{mS} / \mathrm{cm}$ & $1100-1200$ \\
\hline $\mathrm{Ph}$ & $7-8$ \\
\hline
\end{tabular}

\subsection{Synthetic solutions}

Raw groundwater was received in small tank, and then the desired quantities of Iron and manganese were added to get required high concentrations 4,8,12 and $16 \mathrm{mg} / \mathrm{L}$. The source of ferrous Iron and Manganese were ferrous sulfate heptahydrate (FeSO4.7H2O) and Manganese sulfate monohydrate (MnSO4.H2O) respectively.

\subsection{Pilot Startup and Operation}

Two runs were achieved to investigate the ability of natural, cheap and safe materials to remove iron and manganese from groundwater. First, the run was conducted to study the effect of different filter media and flow rates on the removal process. Rice husk, rice straw and pottery were installed and testes under four filtration rates 185, 370,460 and 690 m3/m2/d. In the second run, best filer media that has been chosen in the first run was used with $690 \mathrm{~m} 3 / \mathrm{m} 2 / \mathrm{d}$ flow rate under four concentrations of Iron and Manganese 4,8,12 and $16 \mathrm{mg} / \mathrm{L}$ to investigate the saturation time of each media under different concentrations. Table 3 represents the experimental runs of the study.

Table 3: Experimental runs of the study

\begin{tabular}{|c|c|c|c|c|c|}
\hline Run & Media & $\begin{array}{l}\text { Discharge } \\
\text { (m3/m2/d) }\end{array}$ & $\begin{array}{l}\text { Duration } \\
\text { (hr) }\end{array}$ & $\begin{array}{c}\text { Iron } \\
\text { Concen. }(\mathrm{mg} / \mathrm{L})\end{array}$ & $\begin{array}{c}\text { Manganese } \\
\text { Concen. }(\mathrm{mg} / \mathrm{L})\end{array}$ \\
\hline \multirow{4}{*}{1} & \multirow{4}{*}{$\begin{array}{c}\text { Rice Straw, Rice } \\
\text { Husk, Pottery }\end{array}$} & 185 & 6 & 1.5 & 2 \\
\hline & & 370 & 6 & 1.5 & 2 \\
\hline & & 460 & 6 & 1.5 & 2 \\
\hline & & 690 & 6 & 1.5 & 2 \\
\hline \multirow{4}{*}{2} & \multirow{4}{*}{ Rice Husk } & 690 & 6 & 4 & 4 \\
\hline & & 690 & 6 & 8 & 8 \\
\hline & & 690 & 6 & 12 & 12 \\
\hline & & 690 & 6 & 16 & 16 \\
\hline
\end{tabular}


Citation: Ahmed M. Abo-Elmagd, et al., Removal of Iron and Manganese from Groundwater by Adsorption on Agricultural Residues and Natural Waste Materials.Australian Journal of Basic and Applied Sciences, 13(8): 104-111.DOI: 10.22587/ajbas.2019.13.8.14

The samples were not allowed to settle to simulate the actual case in the well. Atomic absorption spectroscopy and spectrophotometric techniques were used for measuring Iron and manganese concentrations. Also, the pH, turbidity, TDS and conductivity were measured at the site laboratory directly.

\section{RESULTS AND DISCUSSION}

\subsection{Effect of the different flows on the removal of Iron \& Manganese by rice husk filter.}

Rice husk is one of the most common agricultural wastes in Egypt. Despite intensive research for reuse, it is still a major burden on the environment as a result of farmers' habit of getting rid of it by burning.

To evaluate the performance of the rice husk filter, four different flows were used for six hours and one sample was taken every hour. The four flows are 185, 370.460 and $690 \mathrm{~m} 3 / \mathrm{m} 2 / \mathrm{d}$, and the results of iron removal after the first hour were $100 \%$, $96 \%, 91.3 \%$ and $87.3 \%$, respectively. The same flows were applied to evaluate $\mathrm{Mn}$ removal and the results were $100 \%, 96 \%, 91 \%$ and $96 \%$ respectively. Fig. 3 shows these results.
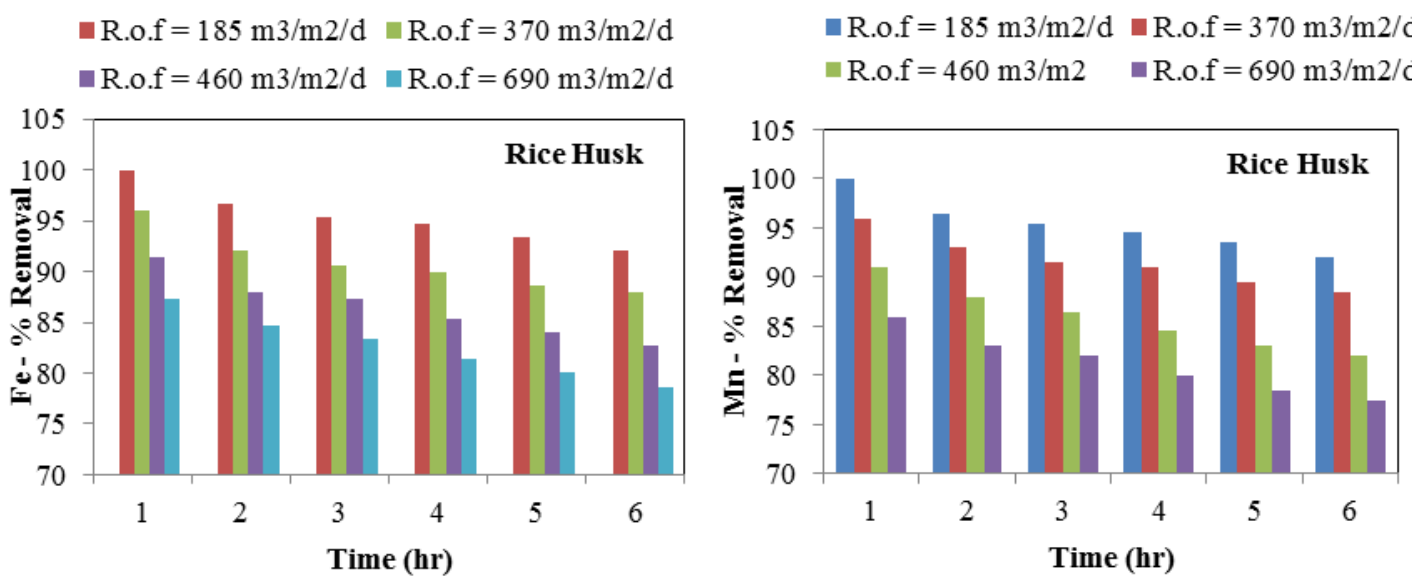

Fig.3: Effect of different flows on iron \& manganese removal percentage by rice husk filter.

\subsection{Effect of the different flows on the removal of Iron \& Manganese by rice straw filter.}

To highlight the performance of rice straw in the adsorption of contaminants in groundwater, the same four flows were applied. The Fe removal ratios were $100 \%, 96 \%, 91.3 \%$ and $87.3 \%$, respectively, and the Mn removal ratios were $97.5 \%, 93.5 \%$, $91 \%$ and $86 \%$ respectively (Badr et al, 2016). Fig. 4 shows these results.
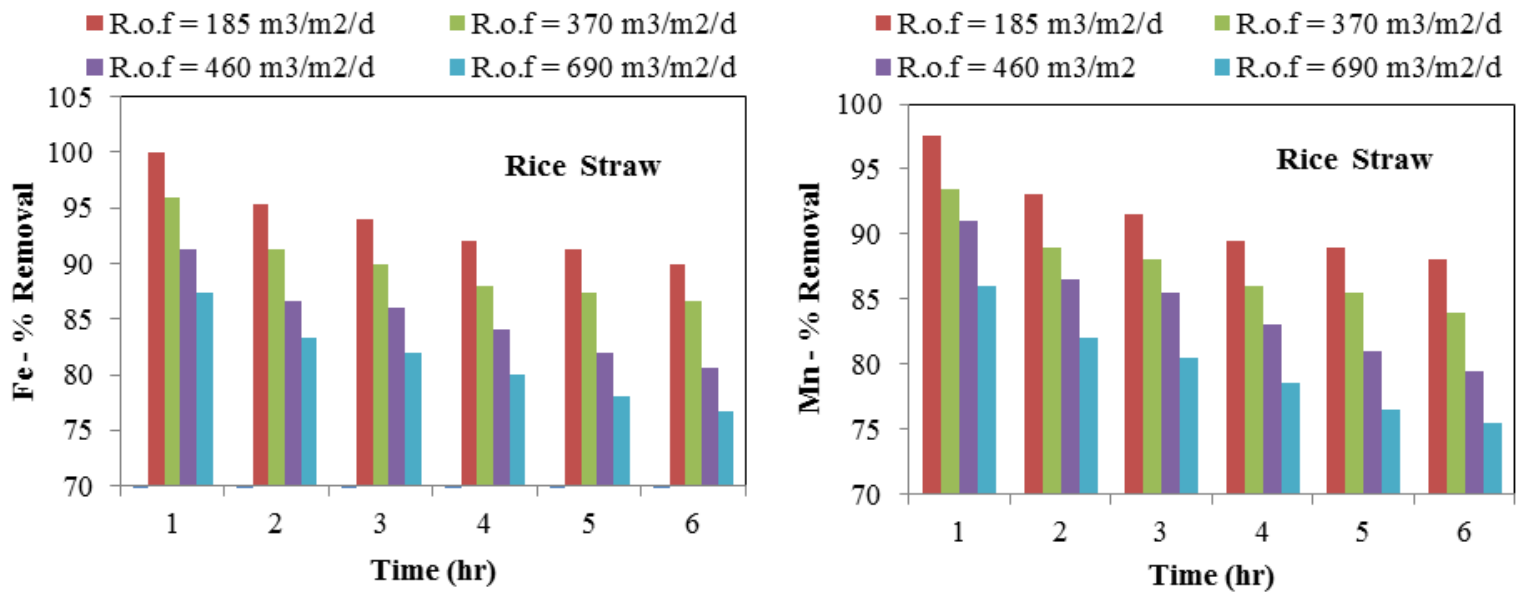

Fig.4: Effect of different flows on iron \& manganese removal percentage by rice straw filter.

\subsection{Effect of the different flows on the removal of Iron \& Manganese by pottery filter.}

Pottery consumption is increasing in the Third World countries in general and especially in Egypt villages where it is commonly used in food and beverage utensils, thus, pottery is cheap, available and common trash in Egypt. In this experiment, the crushed pottery was used as a filtering medium. The same four flows were applied, and the results of iron removal after the first hour were $96.7 \%, 92.6 \%, 88 \%$ and $84.6 \%$, respectively, and the $\mathrm{Mn}$ removal ratios were $94.5 \%, 90.5 \%$, $88 \%$ and $83 \%$ respectively. Fig. 5 shows these results. 

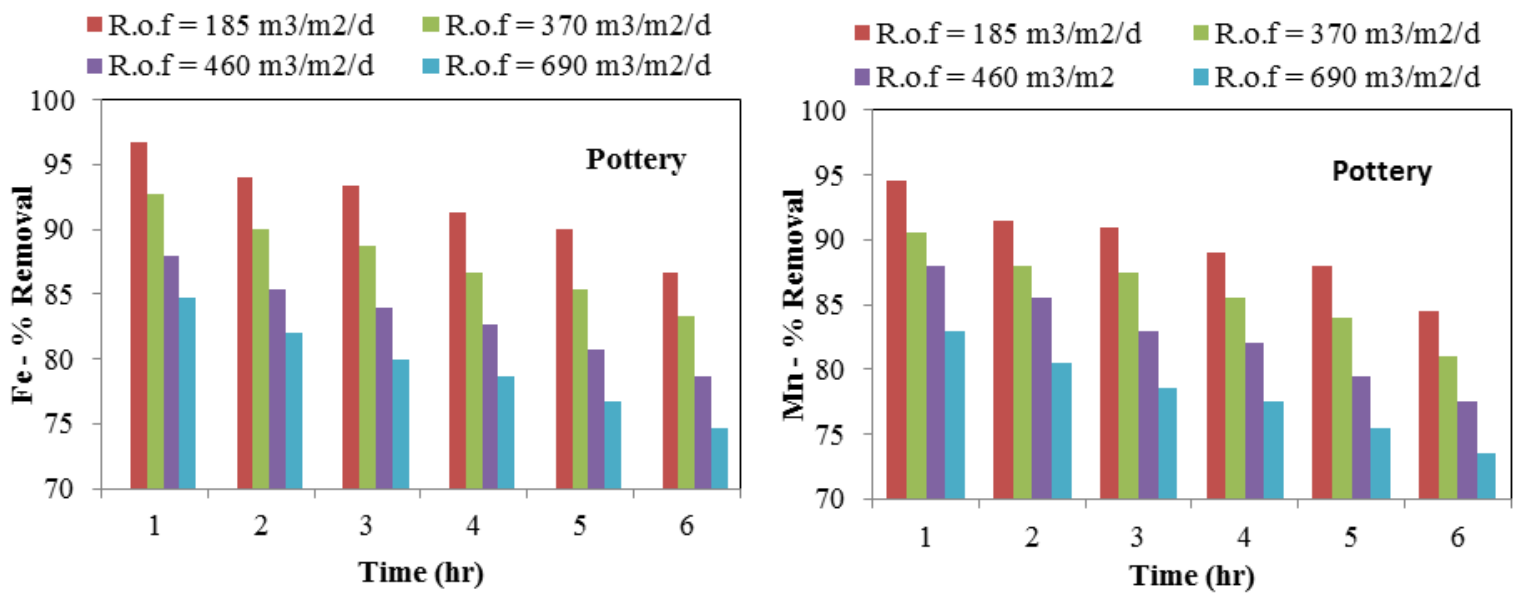

Fig.5: Effect of different flows on iron \& manganese removal percentage by pottery filter.

By comparing the results of $\mathrm{Fe} \& \mathrm{Mn}$ removal shown in fig.(3), fig.(4) and fig.(5), at the first hour the rice husk and the rice straw showed almost the same percentage of the removal, while the pottery showed less removal efficiency. But after 6 filtration hours the rice husk showed the best percentage of removal $92 \%$ followed by rice straw $90 \%$ then followed by pottery $86.7 \%$, for the flow of $185 \mathrm{~m}^{3} / \mathrm{m}^{2} /$ d. Also, the results show a decrease in the efficiency of iron \& manganese removal over time as the flow increases. This indicates the importance of the contact period. The contact time is needed to allow ions to fill the voids on the surface of the adsorbent medium.
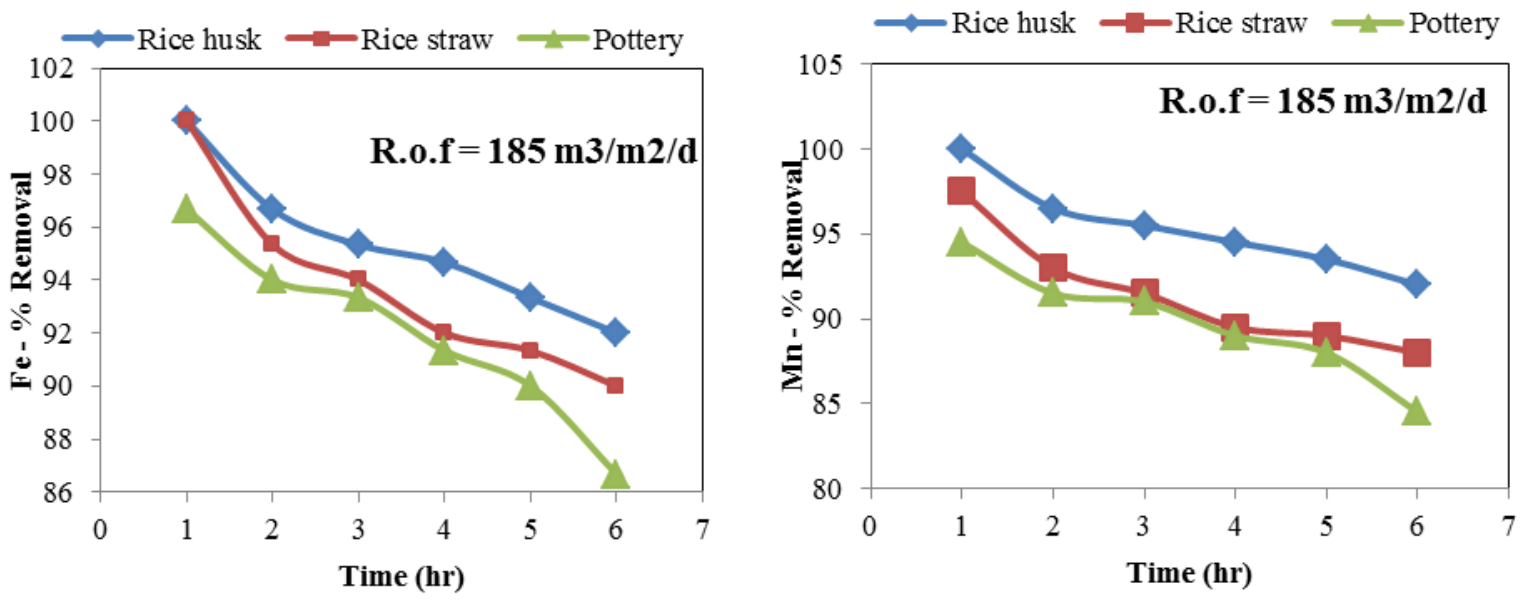

Fig.6: Effect of different filter media on iron \& Manganese removal percentage.

The charts in fig. 6 show the removal efficiency overtime for the first flow rate $185 \mathrm{~m} 3 / \mathrm{m} 2 / \mathrm{d}$. The findings appear a decrease in the efficiency of iron \& Manganese removal over time. This can be explained by the decrease of the active voids on the surface of the adsorbent material over time. The rice husk shows the best removal efficiency more than the rice straw and pottery this because of its high content of carbon ions, about $47.28 \%$ of the total weight (SethiTrupti\& Paul K K, 2014).

\subsection{Effect of filter media used on turbidity}

Fig.7. Illustrate the effect of different filter media on turbidity. It was noticed that all filter medias reduced the turbidity and reached standard value which equals to1 Ntu (WHO Guidelines 2017). The pottery had a big effect on decreasing turbidity. 
Citation: Ahmed M. Abo-Elmagd, et al., Removal of Iron and Manganese from Groundwater by Adsorption on Agricultural Residues and Natural Waste Materials.Australian Journal of Basic and Applied Sciences, 13(8): 104-111.DOI: 10.22587/ajbas.2019.13.8.14

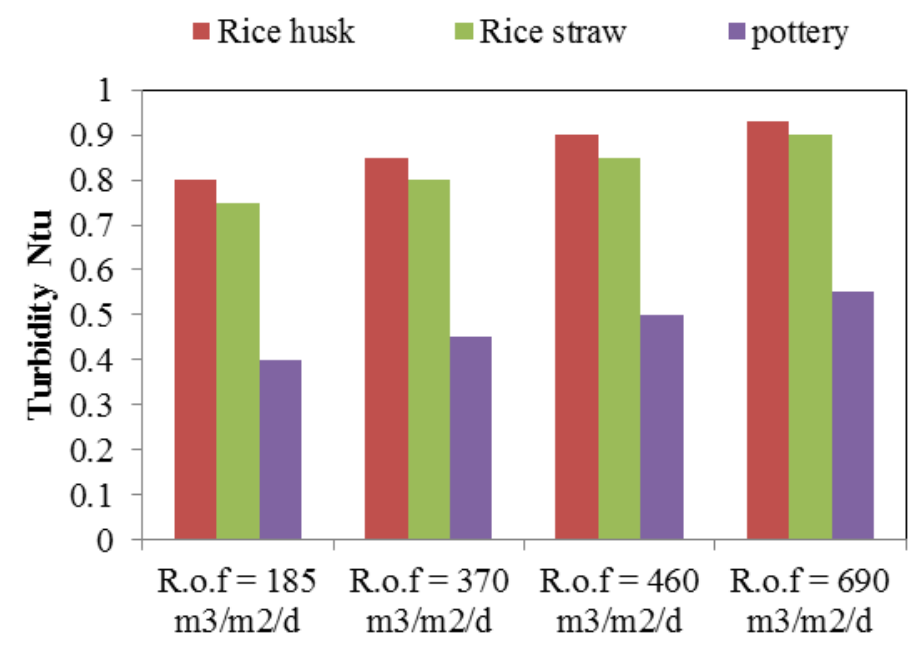

Fig.7: Effect of different flows and filter media on effluent turbidity.

\subsection{Effect of Different Concentrations of Iron and Manganese on Rice Husk Adsorption}
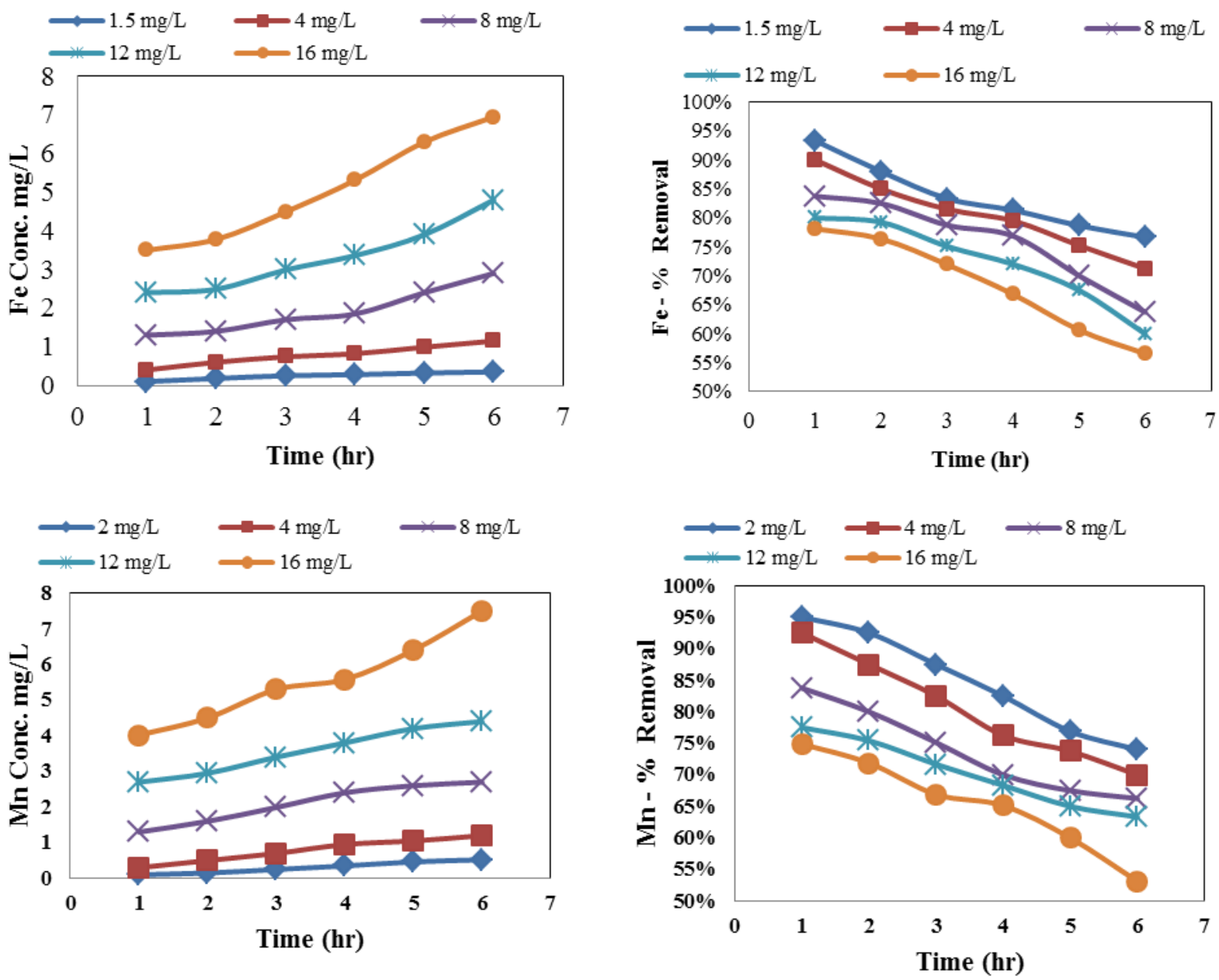

Fig.8: Effect of different iron concentration on removal percentage by rice husk filter media at R.o.f 690 m3/m2/d.

To predict the saturation time of the rice husk which appeared as the best filter media, different iron and manganese concentrations were added at highest filtration rate $690 \mathrm{~m} 3 / \mathrm{m} 2 / \mathrm{d}$. Time of saturation was predicted by applying best fit curve between time and removal percentages to reach the time of zero removal percentage. Best fitting for curves was achieved by Excel function by "Least Squares Fitting function" to find a best-fitting curve for a given set of points, depending on minimizing the squared error .Fig.8 Illustrate the effect of increasing iron and manganese concentration on rice husk adsorption. Table (4) illustrates the initial concentrations of iron and manganese, and the saturation time predicted in each case. 
Table 4: Saturation time of rice husk with Iron and manganese

\begin{tabular}{|c|c|c|}
\hline Inlet Iron or manganese concentration(Mg/l) & Iron Saturationtime(hr) & Manganese Saturation time(hr) \\
\hline $1.5,2$ & 52 & 52 \\
\hline 4 & 40 & 37 \\
\hline 6 & 34 & 33 \\
\hline 8 & 30 & 29 \\
\hline 12 & 26 & 25 \\
\hline 16 & 17 & 16 \\
\hline
\end{tabular}

\section{CONCLUSIONS}

This study achieved success to find local, cheap, frequent and available materials as filter media. Moreover, rice husk and rice straw that was used in filtration still can be used as animal food or may be mixed to be at the allowable safe limit to the animals.

The present study shows that rice husk, rice straw and pottery are effective adsorbents for the removal of Fe (III) and Mn (П) from groundwater. The findings show that operational parameters such as rate of filtrations, contact time and initial concentrations of contaminants, have a great effect on the adsorption efficiency. The amount of Fe (III) and Mn (I) adsorbed increased with the decrease of rate of filtration because of increase of contact time. Rice husk is the best filter media in removing iron and manganese from groundwater, but it needs a very good wash and rinses before use else it will increase the concentration of dissolved salts. Pottery is the lowest filter media in decreasing turbidity. This method saves all chemicals used in oxidation of iron $\&$ manganese. The rice husk filter media saturation time decreased with the increase of initial contaminant.

\section{ACKNOWLEDGEMENT}

All authors acknowledge the laboratory support and examinations funded from Faculty of Engineering, Shoubra, Benha University, Egypt.

\section{CONFLICT OF INTEREST}

Authors declare no conflict of interest

\section{REFERENCES}

Badr E Ezzat, Hanan A. Fouad, Ahmed M. abo-elmagd, Ahmed Y. Bakry (2016) "Utilization of Rice Straw in Removing Iron \& Manganese from Groundwater " ERJ- Faculty of Engineering at Shoubra, Vol 30, Oct.

Barloková D \&Ilavský J (2010).Removal of Iron and Manganese from Water Using Filtration by Natural Materials. Polish J. of Environ. Stud. Vol. 19, No. 6, 1117-1122

BhavnaMistry (2016) Properties and Industrial Applications of Rice Husk. International Journal of Engineering Science and Computing Vol.6, Issue No.10 : 2677 -2679.

BasavaRao, V.V. and Ram Mohan Rao, S. (2006). Adsorption studies on treatment of textile dyeing industrial effluent by flyash. Chemical Engineering Journal, 116(1): 77-84.

Chuah, T.G., Jumasiah, A., Azni, I., Katayon, S. and Thomas Choong, S.Y. (2005). Rice husk as a potentially lowcostbiosorbent for heavy metal and dye removal: an overview. Desalination 175(3): 305-316.

Daifullah, A.A., Girgis, B.S., Gad, H.M., 2003. Utilization of Agroresidues (ricehusk) in small wastewater treatment plants.Material Lett. 57, 1723-1731.

J.Silver. (1993).“Chemistry of Iron.First Edition, Blackie Academie and Professional. ."Mollah, A. H., and Robinson, C. W. (1996). "Pentachlorophenol adsorption and desorption characteristics of granular activated carbon.Isotherms." Water Research, 30(12), 2901-2906.

K.K. Wong, C.K. Lee, K.S. Low and M.J. Haron, "Removal of $\mathrm{Cu}$ and $\mathrm{Pb}$ by tartaric acid modified rice husk from aqueous solutions". Chemosphere(2003), 50 (1) 23-28.

SethiTrupti, Paul K K , 2014. "Characterization and Application of Rice Husk for Removal of Heavy Metals from Laboratory Prepared Waste Water”. National Institute of Technology Rourkela Rourkela-769008,Odisha,India. Roll No-110ce0057.

Sotelo, J.L., Ovejero, G., Delgado, J.A., Martı'nez,(2002).” Adsorption of lindane from water onto GAC: Effect of carbon loading on kinetic behavior". Chem. Eng. J. 87, 111-120.

Tekerlekopoulou A.G and Vayenas D.V., 2006. Ammonia, Iron and manganese removal from potable water using trickling filters, Desalination, 210(1-3), 225-235, doi:10.1016/j.desal.2006.05.047, Elsevier

UNESCO.(2004). "Groundwater resources of the world and their use." Edited by Zekster S, Everett G.".Page 34-55.

WHO. (1996). "Guidelines for drinking water quality:." Health Criteria and other supporting information.WHO, Geneva. , 2nd edition, Vol 2. Zektser, I. S., and Lorne, E. (2004)."Groundwater resources of the world: and their use."IhP Series on groundwater, UNESCO.

WHO Library 2017, Data Guidelines for drinking-water quality: fourth edition incorporating the first Addendum, ISBN 978-92-4154995-0) 
ParameswaranBinod, RaveendranSindhu, Reeta Rani Singhania, SurenderVikram, Lalitha Devi, SatyaNagalakshmi, Noble Kurien, Rajeev K. Sukumaran, Ashok Pandey.(2010) “Bioethanol production from rice straw: An overview”. Journal of Bioresource Technology. Volume 101, Issue 13, Pages 4767-4774 